DOI: $10.30612 /$ rmufgd.v10i19.13035

\title{
Entrevista com Deisy Ventura
}

Entrevistadoras:

Déborah Silva do Monte

Professora adjunta da Universidade da Grande Dourados (UFGD),

Dourados- MS, Brasil.

e-mail: deborahmonte@ufgd.edu.br

Orcid: 0000-0002-4074-5715

Fátima Anastasia

Professora do Programa de Pós-Graduação Stricto Sensu em Relações Internacionais (PPGRI) da Pontifícia Universidade Católica de Minas Gerais (PUC Minas), Belo Horizonte- MG, Brasil. e-mail: fatima.anastasia@gmail.com

Orcid: 0000-0001-5839-9155

Deisy Ventura é Professora Titular de Ética da Faculdade de Saúde Pública (FSP) da Universidade de São Paulo (USP), atualmente exercendo o cargo de Coordenadora do Programa de Pós-Graduação em Saúde Global e Sustentabilidade. É também Professora do Programa de Pós-graduação em Relações Internacionais do Instituto de Relações Internacionais (IRI) da USP, onde fez sua Livre-Docência em Direito Internacional (2012) e lecionou de 2008 a 2018. Foi Presidente da Associação Brasileira de Relações Internacionais - ABRI entre julho de 2019 e julho de 2021, e foi membro de sua Diretoria entre 2013 e 2017. É membro do Comitê de Assessoramento (CA) Direito do CNPq, desde 2019. É Doutora em Direito Internacional e Mestre em Direito Comunitário e Europeu pela Universidade de Paris 1, Panthéon-Sorbonne. Graduada em Direito e Mestre em Integração Latino-americana da Universidade Federal de Santa Maria. Entre maio de 2020 e março de 2021 foi Consultora para temas relacionados à pandemia da Sala de Coordenação e Resposta à Covid-19 (SACROI-Covid-19) da Comissão Interamericana de Direitos Humanos (CIDH). Seus principais temas de pesquisa, atualmente, são a ética da saúde global, em especial os enfoques de direitos humanos das pandemias e das emergências internacionais de saúde pública; a permeabilidade entre as dimensões nacional e internacional da regulação, particularmente no campo da saúde global e da mobilidade humana internacional; e o emprego da arte na formação superior. 
Deborah: Agradeço muito por sua disponibilidade em falar conosco. Eu, a Fátima e um outro colega, o Pedro Matos, estamos organizando um dossiê sobre a cooperação internacional Desafios Contemporâneos - a ser publicado na Monções (Revista de Relações Internacionais da UFGD). É um tema que perpassa as nossas pesquisas, mesmo que, às vezes, com um enfoque mais regional e, às vezes, com um enfoque mais subnacional. Quando lançamos o edital de chamada de artigos, em meados do ano passado, nós não tínhamos ideia da magnitude e da que duração da pandemia. Então, nós temos alguns artigos, no dossiê, que tratam da questão da pandemia, da vacinação, das competições geopolíticas em torno da vacina e da própria questão do protagonismo, ou não, dos entes subnacionais perante a política do governo nacional. A sua contribuição, hoje, vai trazer um contexto muito importante para esses trabalhos do dossiê. [...] Nós lemos a pesquisa, feita em colaboração com outros pesquisadores e outras pesquisadoras, intitulada "Mapeamento e Análise das Normas Jurídicas de Resposta à Covid-19 no Brasil", e ficamos muito impressionadas com as evidências que vocês apresentam para dar sustentação ao seu argumento. Nós gostaríamos de entender a motivação, como surgiu a iniciativa dessa pesquisa e, de lá pra cá, como ela foi desenvolvida, o que se manteve, o que mudou, pra gente começar a nossa conversa.

Deisy: Acho que quando nós começamos essa pesquisa, não tínhamos ideia do que iríamos encontrar. $\mathrm{Na}$ verdade, o fato de eu ter decidido estudar as emergências sanitárias internacionais, há 12 anos, acabou me colocando numa posição muito, digamos assim, privilegiada para olhar o que começava a acontecer ali em março e abril de 2020. Nós temos poucos pesquisadores no Brasil na área de Ciências Sociais e Humanas que estudaram as emergências anteriores, como a pandemia de gripe H1N1, a crise do ebola na África Ocidental, a síndrome congênita do vírus no Brasil, que foram temas aos quais eu me dediquei. Então, quando começou a emergência, pude observar os resultados desse fenômeno sobre os direitos humanos em razão dos impactos nefastos constatados nas emergências internacionais anteriores. Também me impressionava muito que falassem tanto da Covid-19 sem mencionar as emergências internacionais anteriores, como se a pandemia fosse algo 
totalmente inesperado, quando, na verdade, esta emergência, mais do que previsível, foi prevista. Temos documentos de organizações internacionais prevendo a ocorrência de uma pandemia como esta há mais de 20 anos. Desde 2016, por exemplo, o Banco Mundial possui uma linha de crédito que financia a preparação de Estados para resposta às pandemias. Ou seja, para nós que estudamos a saúde global, era algo óbvio. Talvez não tanto no ambiente das ciências sociais e humanas, exceto os colegas que estudam o meio ambiente, que já vinham com essa consciência de que a deterioração ambiental acarretava, entre outras coisas, a emergência e a reemergência de doenças. No meio científico, digamos assim, nas ciências duras, era claro. Obviamente, quem trabalhava com doenças emergentes e reemergentes tinha essa clareza absoluta, então, para nós, a questão não era 'se', a questão era 'quando'. Havia uma grande probabilidade de que fosse um coronavírus, a gente não poderia saber qual vírus, ou quando iria começar, nem indicar um local preciso, mas sabíamos que ocorreria. No nosso século, já havia ocorrido a gripe H1N1, que eu estudei muito, fiz a minha livre docência e publiquei um livro sobre ela ${ }^{1}$. E todos os elementos já estavam ali, então a Covid-19 vinha surgindo sem nenhuma novidade. Justamente porque os governos e as organizações internacionais estavam respondendo a ela sem levar em conta tudo o que a gente já tinha aprendido sobre o impacto dessas emergências, me pareceu evidente que o impacto sobre os direitos humanos seria terrível. Então pensamos: é preciso acompanhar desde o início o impacto sobre os direitos humanos. No Centro de Estudos e Pesquisa de Direito Sanitário (CEPEDISA) da Faculdade de Saúde Pública da USP os pesquisadores têm uma experiência enorme em acompanhar a legislação epidemiológica brasileira. O CEPEDISA chegou a apresentar uma proposta, ainda durante o governo Lula, de mudança da legislação epidemiológica brasileira, que foi parcialmente aproveitada em instrumentos esparsos. Assim, já tínhamos plena consciência do despreparo da nossa legislação epidemiológica para um episódio como esse. Discutindo com o Professor Fernando Aith, que é o diretor do CEPEDISA, e com outros colegas que se somaram a nós, como a Professora Rossana Rocha Reis, do Departamento de Ciência Política da USP, que vem trabalhando com direitos humanos há

\footnotetext{
${ }^{1}$ VENTURA, D. 2013. Direito e saúde global - o caso da pandemia de gripe A(H1N1). São Paulo: Dobra Editorial/Expressão Popular.
} 
muito tempo, além de colegas do Departamento de Epidemiologia, nos pareceu que uma forma de acompanhamento dos direitos humanos seria acompanhar a legislação, porque a primeira expressão da resposta brasileira à pandemia foi justamente a nova lei da quarentena, em 6 de fevereiro ${ }^{2}$. Essa lei foi uma experiência fascinante, porque o governo apresentou um projeto que foi convertido em lei em poucos dias. Mas nas poucas horas em que esse projeto de lei foi discutido na Câmara, os deputados conseguiram colocar ali dentro elementos da maior importância como o respeito aos direitos humanos, o dever de informação e de transparência dos dados. Então, uma pequena brecha democrática já havia melhorado essa lei e nós nos convencemos de que um acompanhamento seria necessário. Fomos buscar parceria, porque infelizmente as agências de fomento já estavam com poucos recursos e têm uma resposta muito lenta. Então buscamos a parceria com a Conectas Direitos Humanos, uma ONG que tem experiência enorme nesse tema e que conseguiu recursos. Montamos uma equipe e começamos a coletar normas, mas não tínhamos ideia de que chegaríamos a esta quantidade. Realmente, hoje olhando pra trás foi uma loucura o que fizemos. Temos mais de 3.600 normas federais até abril de 2021, e milhares e milhares de normas estaduais. Desde janeiro de 2021, o projeto passou a ser financiado pelo CONASS (Conselho Nacional de Secretários de Saúde) para complementação do seu banco de dados, com a intenção de disponibilizá-los ao público em uma plataforma na internet. Então, começamos assim, com a ideia de identificar os regimes jurídicos excepcionais e tentar medir o seu impacto sobre os direitos humanos, entre outras razões porque, depois da crise sanitária, há a tendência de que os regimes excepcionais persistam, ou seja, que a situação seja aproveitada para fazer retroceder a ordem democrática em diversos aspectos.

Fátima: Para passar a boiada?

${ }^{2}$ Lei 13.949/2020, disponível em http://www.planalto.gov.br/ccivil_03/_ato2019-2022/2020/lei/l13979.htm 
Deisy: Exatamente. Mas no começo não tínhamos ideia do que viria a nos acontecer, porque há uma diferença enorme entre um governo cometer erros ao tentar conter uma pandemia e um governo cometer o erro de não tentar conter uma pandemia. É sabido que a ampla maioria dos países cometeu erros ao implementar decisões de contenção da doença. Há um relatório muito importante do painel independente que avaliou a resposta da OMS e dos Estados à pandemia, divulgado em maio de $2021^{3}$. Em resumo, ao avaliar o desempenho dos Estados na resposta à Covid-19, ele identifica três grupos de países. Primeiro, há o grupo pequeno de países que optaram pelo confinamento mais radical, que são de fato os que conseguiram conter a doença com maior eficácia. Depois há o maior grupo de países que promoveu uma resposta híbrida, que teve momentos de confinamento, momentos de reabertura etc. $E$ por fim há os negacionistas, entre os quais o Brasil está, que são um fracasso total. Mas há dezenas de países importantes que ficaram nessa resposta híbrida. Mesmo assim, quando eles cometem erros, eles cometem erros numa tentativa de conter a propagação da doença. Entretanto, o Brasil ter optado por não conter a pandemia foi algo realmente desconcertante. Claro que esta posição se traduziu na legislação e também no elevado grau de judicialização da pandemia. O projeto começou em abril de 2020 com a coleta de normas. Mas a conjuntura foi se deteriorando, vimos o que estava acontecendo com o [Luiz Henrique] Mandetta no Ministério da Saúde. Observando o Diário Oficial, via-se também atos de governo, atos de gestão que precisam ser publicados. E fomos acompanhando também, claro, o noticiário. Dentro da Faculdade de Saúde Pública, muitos colegas estão envolvidos na gestão do SUS [Sistema Único de Saúde] de diferentes formas. Entre maio e junho, nos demos conta do que estava acontecendo. E desde então, começamos a alertar para o fato de que a propagação da Covid-19 era a intenção do governo federal. Lembro que concedi uma entrevista à Eliane Brum em julho de $2020^{4}$ e fui muito criticada, porque nessa entrevista eu falei da existência de um plano de ataque sistemático à população civil. Na época, houve pouquíssimo espaço na imprensa para este tipo de constatação, que com o passar do tempo foi ficando cada vez mais

\footnotetext{
${ }^{3}$ Disponível em https://theindependentpanel.org/

${ }^{4}$ Disponível em https://brasil.elpais.com/brasil/2020-07-22/ha-indicios-significativos-para-que-autoridadesbrasileiras-entre-elas-o-presidente-sejam-investigadas-por-genocidio.html
} 
evidente. Tudo isso é para falar do que nos levou a fazer a linha tempo da intencionalidade da propagação da Covid-19 no Brasil, que é só uma parte de todo esse projeto Direitos na Pandemia. O projeto está estudando muitas outras coisas, como os impactos destas normas sobre as populações vulneráveis [...]. Ao final do ano de 2020, passou a ser predominante na mídia a ideia de que o governo havia sido negligente, de que o governo havia cometido erros, e especificamente em relação ao Presidente, que a fala dele era meramente provocativa. E o governo repetia muito isso, o Ministro da Saúde da época, General Eduardo Pazuello, dizia que as palavras do presidente eram ditas para a internet, eram provocações, digamos assim, e o que interessa é o que o governo estaria fazendo. O presidente chegou a dizer "eu não matei ninguém". Chegou a dizer que palavras não matam. E nós pensamos: está na hora de fazer uma linha do tempo para cotejar as declarações do presidente com os atos de gestão e os atos normativos, e mostrar sua coerência. Na primeira versão, que foi apresentada em janeiro de 2021, pesquisamos as declarações de autoridades federais por meio de plataformas de busca na internet, mas ela é mais focada nos atos normativos, que eram a nossa base de dados mais forte naquele momento. Demonstramos que havia uma pluralidade de atores de governo envolvidos, que não era só o presidente, inclusive não era só o presidente que encorajava a infecção pelo vírus.

Fátima: Gostaríamos de saber quais são esses atores mais importantes.

Deisy: O que se identifica claramente, entre outras formas por meio da transcrição das lives organizadas pelo Presidente com seus convidados, é a atuação de diversas autoridades, principalmente do Ministério da Economia e do Ministério da Saúde. O Ministério da Saúde é hoje um ministério subalterno, então temos um envolvimento enorme do Ministério da Saúde nessa estratégia. Há uma alteração quando entra o Marcelo Queiroga, mas é uma alteração muito menor do que ela parece ser, porque supostamente Marcelo Queiroga faz a primeira campanha de prevenção, mais de um ano depois do início da doença. Supostamente, ele faz 
a primeira campanha de prevenção, mas quando se analisa os dados, constata-se que houve uma ação judicial, movida pelo Ministério Público Federal, que condenou a União a fazer essa campanha.

Deborah: Então é uma reação...

Deisy: Exatamente, esse é o ponto. As ações do governo que não eram ações de propagação do vírus invariavelmente eram reações à pressão de outros atores. Quando o governo agia espontaneamente, agia sempre pela propagação. Para negar esta afirmação, o Ministério da Saúde costuma arrolar tudo o que o governo federal fez em matéria de assistência, principalmente a abertura de leitos de UTI, o repasse de recursos para os estados, entre outras coisas que são obrigação do governo federal, e que estão no campo da assistência, nunca da prevenção, e não se pode confundir as duas esferas. Afirmar que o governo não propagou o vírus porque ele abriu leitos de UTI é uma resposta que não corresponde à pergunta. Em geral, quando o governo federal agiu no campo da prevenção é porque ele foi alvo de alguma ação judicial, de uma determinação clara do Tribunal de Contas da União ou de alguma outra forma de pressão. Mas mesmo no plano da assistência, o governo agiu sempre de forma tardia e de insuficiente. Na atualização do nosso estudo, feita a pedido da CPI do Senado Federal em maio de 2021, foram identificadas falas de diversas autoridades, entre elas do líder do governo na Câmara, do presidente do Banco do Brasil, do ministro do turismo, de assessores presidenciais, então temos claramente um envolvimento amplo, trata-se de uma estratégia institucional. E dentro do governo federal, cada autoridade que se insurge é descartada: ou ela é demitida estando já dentro do governo, ou ela sequer entra no governo, é anunciada e é descartada. Então não há nenhuma dúvida sobre a estratégia institucional, mas eu diria que os atores mais importantes, os líderes dessa estratégia, são o presidente da República, a Casa Civil e o ministro da economia. O ministro da economia tem uma atuação que está ficando mais clara nas últimas semanas, mas não era tão clara assim. Demonstramos o quanto o 
Ministério da Economia defendia a imunidade de rebanho, e também se somava às falsas previsões de término da pandemia, repetindo em diversos momentos: "A pandemia está terminando". Em novembro de 2020, por exemplo, o secretário de política econômica do Ministério da Economia afirmou que alguns Estados do Brasil já estavam alcançando a imunidade de rebanho ${ }^{5}$. É uma prova muito importante da existência de uma estratégia intencional, porque a vacinação ainda não havia começado, então só poderia estar falando da imunidade de rebanho por contágio. O secretário chega a afirmar que a imunidade de rebanho seria alcançada quando $20 \%$ da população fosse contaminada. Além de mentir que a imunidade já está sendo alcançada, ele mais uma vez afirma, como o ministro da economia afirmou muitas vezes, que as chances de uma nova onda da doença são mínimas.

Fátima: E o ex-ministro das relações exteriores, Ernesto Araújo?

Deisy: Eu não o considero um dos atores mais importantes. É mais para o final do ano de 2020 que ele adquire um certo protagonismo na tentativa frustrada de trazer as vacinas da Índia. É verdade que ele fez críticas à OMS, principalmente escreveu um artigo extraordinário chamado "Chegou o comunavírus"6. Com certeza é um partícipe, como citamos no relatório, mas eu não o identifico como um dos atores principais. Vejo a liderança mais no Ministério da Economia, na presidência da República, na Casa Civil e, claro, no Ministério da Saúde, indubitavelmente. Mesmo que a militarização tenha acontecido no Ministério da Saúde para colocá-lo em uma linha de comando que vinha do Palácio do Planalto, ele acaba sendo um líder na medida em que ele se omite no seu papel fundamental de prevenção da doença e se coloca a serviço da difusão do tratamento precoce. Quer dizer, o mundo inteiro lida com negacionistas, lida com fake news, mas é extraordinário que fake news e defesa de um

\footnotetext{
${ }^{5}$ Ver, por exemplo, Chance de nova onda de Covid é baixíssima, diz secretário de Guedes, Folha de S.Paulo, 17/11/2020, disponível em https://www1.folha.uol.com.br/mercado/2020/11/chance-de-nova-onda-de-covide-baixissima-diz-secretario-de-guedes.shtml

${ }^{6}$ Disponível em https://funag.gov.br/index.php/pt-br/2015-02-12-19-38-42/3636
} 
tratamento sem eficácia para a Covid venham da institucionalidade, se tornem informações oficiais. O próprio ministro da saúde interino, General Eduardo Pazzuello, em sua solenidade de posse como titular do cargo defende o tratamento ineficaz e transmite diversas ideias errôneas sobre a resposta à Covid-19. Na mesma ocasião, o Presidente da República faz um agradecimento especial ao Deputado Federal Osmar Terra [hoje apontado como membro do "gabinete paralelo" investigado pela CPI]. Então, eu posso falar de atores principais, mas o governo federal esteve inteiro nessa estratégia.

Fátima: Isso é muito impressionante. Agora, uma pergunta que a gente faz, obviamente, é se não há algum interesse econômico por trás da adoção desse tratamento precoce. Como explicar, Deisy, essa reincidência em algo que vai contra o consenso científico na matéria?

Deisy: Eu acho que fica claríssima a razão, Fátima. Isso está no livro do Mandetta, que ele publicou ainda em setembro de 2020. Ele conta que o presidente dizia: com essa caixinha na mão, o trabalhador brasileiro terá coragem de voltar ao trabalho. Então, quando essa estratégia começa, no ano passado, a motivação é clara: dar às pessoas a coragem para que se exponham ao vírus.

Fátima: Porque estariam protegidos, suspostamente.

Deisy: Porque dessa forma, ele teria uma narrativa muito favorável, que é a narrativa de que quem teve caso grave, ou morreu, é porque não usou o tratamento precoce, valendo-se da suposta dúvida científica sobre o tratamento. (...) Eu acho que há três elementos que explicam facilmente o que aconteceu. Primeiro, a necessidade de dar coragem à exposição, que era crucial na estratégia. Segundo, o predomínio de interesses econômicos, tanto de quem fabrica estas substâncias, quanto de quem as prescreve. Muita gente ganhou muito dinheiro 
prescrevendo tratamentos comprovadamente sem eficácia para a Covid-19, explorando o desespero das pessoas. E o terceiro elemento é justamente que o ser humano, diante de uma catástrofe, em grande medida, deseja acreditar que existe um tratamento, e o charlatanismo fala o que se quer ouvir.

Deborah: Excelente, Deisy. Muitas perguntas que tínhamos formulado já foram respondidas ao longo da sua fala, mas eu gostaria de ver, já que você vem estudando a questão das epidemias por um longo tempo, e tem um conhecimento grande sobre o funcionamento do Sistema Único de Saúde brasileiro, eu gostaria de entender como essa política pública potencializou a postura brasileira na temática da saúde global até o governo Bolsonaro. E se há um processo também pela política externa e pela política de gestão da pandemia de desconstrução do SUS e de outras políticas de saúde que demoraram muito tempo para ser construídas, consolidadas, vem ali da redemocratização, vem de muito debate com a sociedade civil, vem de um momento de democratização dos processos, em todos seus níveis de articulação com os entes federativos. Se há um processo de destruição com essas ações, até que ponto a política é resiliente às ações do Bolsonaro, ou se há uma destruição, uma desconstrução das capacidades estatais a um ponto de termos que reconstruí-las do zero depois que isso acabar.

Deisy: Deborah, há diversas perguntas contidas na sua pergunta. A primeira parte posso responder citando a tese de doutorado da Fernanda Aguilar Perez, defendida no IRI/USP em 2018, no programa de duplo diploma com o King's College London ${ }^{7}$. Fernanda afirma que houve uma "política externa de saúde" no Brasil entre 2003 e 2014, envolvendo uma variedade de atores que vai além do Ministério das Relações Exteriores. São atores com protagonismo na área da saúde, como é o caso da Fiocruz (Fundação Oswaldo Cruz), da Assessoria Internacional do Ministério da Saúde, do Instituto Nacional do Câncer e de muitos outros que, de regra, não fazem parte da política externa geral, com suas singularidades, com

\footnotetext{
${ }^{7}$ Disponível em https://www.teses.usp.br/teses/disponiveis/101/101131/tde-29112018-112653/pt-br.php
} 
objetivos diferentes e principalmente com uma afinidade em relação aos princípios do SUS. Então, a nossa política externa de saúde era orientada, além dos princípios gerais de orientação das relações exteriores brasileiras, pelos princípios do SUS. E é isso que a Fernanda demonstra com pesquisa documental, entrevistas etc. Esse paralelismo obviamente se perdeu, pois a política externa do governo Bolsonaro não é uma política externa vinculada aos objetivos do SUS, a começar pelo foco no ataque sistemático aos direitos sexuais e reprodutivos das mulheres, inclusive por meio da adesão à aliança conservadora liderada por Donald Trump à época em que era presidente dos Estados Unidos. Enquanto Ernesto Araújo foi ministro, depois da posse de Joe Biden, o Brasil buscou a liderança dessa aliança internacional conservadora que propõe uma nova interpretação do que seriam os direitos humanos, à luz de uma concepção retrógrada e desumana do que seria uma família. Neste sentido, a posição do Brasil se tornou ofensiva no sentido de violar a concepção de direitos humanos que está na raiz dos princípios do SUS, como a equidade, a universalidade, a integralidade e a participação popular. Em relação a como o SUS se coloca em meio à crise sanitária, a primeira questão que precisamos entender é que ele evitou uma catástrofe ainda pior. Esta afirmação é bem objetiva, não é uma avaliação subjetiva. Em um sistema de saúde, para resposta à emergência, é necessária uma estrutura pré-existente com grande capilaridade territorial e uma rede de profissionais de saúde com formação e experiência. Claro que qualquer emergência requer um contingente adicional de profissionais, mas num país com mais de 200 milhões de habitantes e com um território continental não se forma pessoas com tamanha velocidade em quantidade suficiente, é totalmente impossível. Outra coisa que não se inventa de uma hora para a outra é a experiência federativa.

Fátima: A rede federativa do SUS, que é uma coisa fantástica.

Deisy: Exatamente, não quero usar a palavra logística, porque ela foi totalmente desvirtuada, mas eu vou dizer de outra forma: é uma experiência de trabalho em rede, que é essencial. 
Então, obviamente, a esfera federal não se valeu dessa qualidade, embora os estados e os municípios tenham se valido dentro dos seus limites. O CONASS teve uma atuação importante, o CONASEMS [Conselho Nacional de Secretarias municipais de Saúde] teve uma atuação importante, o Conselho Nacional de Saúde igualmente. Essa estrutura pré-existente evitou o pior, mas ela não foi capaz de evitar meio milhão de mortes. Por isto é criminoso responsabilizar o SUS pela catástrofe sanitária, como Pazuello tentou fazer algumas vezes, como Marcelo Queiroga tentou fazer diversas vezes. Quem pensa que Marcelo Queiroga é menos nefasto do que quem o precedeu está completamente equivocado: é pior ainda, surgiu como um lobo em pele de cordeiro.

Fátima: Basta ver a atuação dele na CPI.

Deisy: Exatamente, e no cotidiano do Ministério da Saúde, pela forma como se alinha sistematicamente ao Palácio do Planalto, apesar de ser médico. A cadeia de comando não foi alterada. O Programa Nacional de Imunização, evidentemente, foi possível graças à nossa larga tradição em imunização. Essas qualidades do SUS evitaram que a crise fosse pior, mas não foram capazes de evitar a catástrofe sanitária, porque a diretriz federal era disseminar o vírus. Uma coisa é a omissão do governo federal, outra coisa é uma ação em prol da disseminação da doença. Conforme a legislação vigente, a cabeça do SUS é o Ministério da Saúde, e ele não valorizou os trunfos do SUS na resposta, como Mandetta anunciou que pretendia fazer. Por exemplo, se nós olharmos para a questão do financiamento, o que o SUS vem sofrendo começa muito antes do governo Bolsonaro e encontra o seu ápice na famosa 'PEC da morte' [Emenda Constitucional n.o 95 ou Emenda Constitucional do Teto dos Gastos Públicos], ou seja, na fixação do teto de gastos, que sufoca o SUS e vai transformando o subfinanciamento em desfinanciamento. Então, esse problema é anterior à pandemia, mas ele poderia ser enfrentado graças aos recursos extraordinários para a resposta à Covid-19. Injetando recursos extraordinários no SUS e utilizando a rede de atenção primária à saúde, 
que é uma das grandes qualidades do sistema e uma das grandes vítimas dos cortes de investimentos em saúde, o resultado seria diferente. Então, os trunfos que o SUS construiu, e que estavam enfraquecidos pela falta de financiamento e desvalorizadas de diversas formas, poderiam ter sido reabilitados, reforçados, valorizados rapidamente, mas isso seria prevenção, isso seria para conter a doença.

Fátima: Que não era a intenção do governo.

Deisy: Que não era o objetivo. Na resposta do governo, a ideia essencial era propagar a doença. Ainda que se estime uma letalidade baixa para uma doença, quando um índice de letalidade é aplicado a uma população de mais de 200 milhões de habitantes, esta decisão implica um grande número de mortes e de sequelas evitáveis, em razão da doença e também da sobrecarga do sistema de saúde, que também gerou mortes evitáveis. Implica também um número maior de profissionais da saúde mortos e com sequelas, além de um gasto absurdo em assistência. Por que eu vou gastar com UTI se eu posso gastar com máscaras? É um gasto público enorme, de um sistema que já tem recursos escassos. Houve, em algumas localidades, colapso do sistema. Então, claro que essa escolha é altamente nociva para o sistema de saúde, é a sobrecarga dos profissionais, é o colapso em alguns casos, é o gasto absolutamente desnecessário e excessivo. E obviamente gera questões como a necessidade de hospitais de campanha, de aumento de leitos de UTI, que numa estratégia de prevenção adequada seriam necessários em algumas localidades, pontualmente, mas que se tornaram comuns no Brasil, com enorme gasto público. Até que se chega ao escândalo da falta de insumos, com mortes por falta de oxigênio e até por falta de kit de intubação. Então, com certeza não se diz declaradamente "nós queremos acabar com o SUS", mas se escolhe uma estratégia que, além de ser criminosa em relação à pandemia em si - porque propagar a doença implica causar mortes que poderiam ser evitadas, dores e sofrimentos que poderiam ser evitados - claro que atenta contra o SUS. Paralelamente, o que se vê de forma reiterada é o ministro da economia 
declarar que é a favor do vaucher ${ }^{8}$ para cobrir gastos em saúde, que poderia ser usado em hospitais privados ou públicos. É óbvio que um sistema que vai da prevenção até a UTI, passando pelo pioneirismo em transplantes de órgãos, pela pesquisa de ponta em diversos temas, entre outras qualidades, está no extremo oposto a um vaucher, sobretudo em relação à ideia que o presidente repete muitas vezes, de que o Estado não pode cuidar de todos os brasileiros, da saúde como responsabilidade individual. O SUS representa o direito universal à saúde consagrado pela Constituição Federal de 1988. Embora, quando questionado, o ministro da economia diga "não, não, eu nunca falei em terminar com o SUS", mas principalmente quando ele fala mais à vontade, ele repete a ideia do vaucher. Uma figura que, quando foi ministro da saúde do Temer, deixou isso muito claro foi o Ricardo Barros, hoje líder do governo. Ele formulou claramente que o SUS não poderia continuar como está ${ }^{\text {. Defendeu }}$ algo alinhado com uma proposta conhecida internacionalmente, de cobertura universal de saúde, que por vezes substitui expressões como o direito à saúde ou a defesa de sistemas públicos de saúde. A cobertura universal pode assumir a forma de uma espécie de seguro saúde para pessoas com baixa renda, como são os planos de saúde baratos e com cobertura mínima, chamados de planos de saúde populares.

Fátima: Eles estão querendo desconstruir o SUS, política na qual o Brasil é referência internacional. Porque essa relutância e essa negação inicial relativas à compra de vacinas, ao ponto de se descobrir, agora, que o interesse estava em comprar vacinas com propina. Essa recusa à vacinação também é um desrespeito ao SUS, que estava preparado para vacinar a população muito antes do que estamos fazendo agora, com essa lentidão e com essa dificuldade. Quer dizer, existe toda uma estrutura de saúde preparada para vacinar

\footnotetext{
${ }^{8}$ Ver, por exemplo, Não tem gestão na saúde pública, setor privado é solução, diz Guedes, R7, 27/04/2021, disponível em https://noticias.r7.com/brasil/nao-tem-gestao-na-saude-publica-setor-privado-e-solucao-dizguedes-27042021

${ }^{9}$ Ver, por exemplo, Tamanho do SUS precisa ser revisto, diz novo ministro da Saúde, Folha de S. Paulo, 17/05/2016, disponível em https://www1.folha.uol.com.br/cotidiano/2016/05/1771901-tamanho-do-susprecisa-ser-revisto-diz-novo-ministro-da-saude.shtml
} 
rapidamente, parece que o SUS poderia vacinar de um milhão a dois milhões de pessoas por dia, se tivesse a vacina, e as pessoas estão morrendo porque as decisões não foram tomadas.

Deisy: As decisões foram tomadas...

Fátima: Mas as decisões de comprar as vacinas não foram tomadas, não por descuido, não por inconsequência, não foram tomadas intencionalmente. Então, nesse sentido, é que você afirma que foram tomadas as decisões de não comprar.

Deisy: Exato. Por exemplo, no caso da Coronavac, o Ministro da Saúde contrata, mas o presidente vai lá e suspende a compra.

Fátima: Bolsonaro o desautoriza.

Deisy: "Quem manda sou eu", e toma a decisão. Mas eu acho, Fátima, que o presidente continua sendo contrário à vacinação, ele continua operando contra a vacinação, não apenas porque ele se nega a dar o exemplo ao se vacinar publicamente, mas porque ele continua levantando suspeitas sobre as eficácias das vacinas, principalmente sobre a Coronavac. $\mathrm{Na}$ verdade, quando alguém levanta suspeitas sobre a vacina que está disponível para a ampla maioria dos brasileiros, é óbvio que está atacando a vacinação como um todo. Isso só vai mudar mais adiante, a partir de uma leitura eleitoral do que aconteceu no final de 2020, de que a população brasileira é favorável à vacinação, e aí surge um rival, que é João Dória [governador do Estado de São Paulo]. O presidente deixa acontecer a vacinação, inclusive porque ele sabe que se a questão for levada ao Supremo Tribunal Federal, ele seria derrotado, mas até então fez de tudo para que essa não fosse a resposta brasileira, por uma série de 
razões. A primeira delas é que a vacina atrapalha o plano de disseminação do vírus. 0 presidente não cansa de repetir, ele continua, um ano depois, afirmando que a melhor forma de imunização é contrair a doença.

Deborah: Falou isso semana passada.

Deisy: Exatamente, ele continua, ele não para. Não é por falta de provas que vamos deixar de responsabilizá-lo. Por outro lado, a vacinação é também um investimento público na resposta, e esta não é uma questão menor. Para mim, o que ele está fazendo é o que se chama de neoliberalismo epidemiológico, em conformidade à diretriz atual do Ministério da Economia de redução mínima possível da atividade econômica, que é deixar a doença seguir o seu curso natural, assim como o neoliberalismo deixa o mercado agir com regulação mínima.

Fátima: Os mais fortes sobreviverão, o Darwinismo social.

Deisy: Não quer cuidar dos mais vulneráveis, não quer ter ações de reequilíbrio, e assim "os melhores vão sobreviver". Elementos de Darwinismo social também, sem dúvida, na ideia de que seria positivo para a sociedade brasileira que as pessoas que têm comorbidades, as pessoas idosas, enfim, que pessoas supostamente mais vulneráveis à doença desapareçam. É uma ideia que acompanha o discurso do presidente há muito tempo, por exemplo na célebre entrevista dos anos 90, quando afirmou que 30.000 pessoas teriam que morrer para o Brasil encontrar o seu caminho. Há também o fato de que valorizar a vacina é também valorizar a ciência, e esse é um governo que, em função do teor ideológico das políticas públicas de saúde, necessita desacreditar a ciência. Porque se eu levar em conta a ciência, não vou defender essa política para drogas, não posso defender essa política para direitos sexuais e reprodutivos. Então a ciência não pode ser valorizada para haver a ideologização definitiva 
das políticas públicas de saúde. Neste sentido, a vacina é justamente o contrário de tudo o que o governo valoriza em todos os aspectos.

Fátima: É valorizar a vida.

Deisy: É valorizar o SUS também, porque sabemos vacinar. O Brasil é capaz de vacinar milhões de pessoas num dia, então, também é mostrar essa rede para a população em geral, dar uma visibilidade positiva. Agora todo mundo, todo brasileiro vai lá e enxerga como funciona, tira selfie, muitos saem dizendo "viva o SUS", e que bacana. Mas isso já existia, quero dizer, essa rede extraordinária, capaz de rapidamente disseminar ações e protocolos em um território continental. Só que muitos, aliás a maioria dos brasileiros que tem voz e voto, dificilmente conhece uma unidade de saúde, só conhece os defeitos do SUS que são alardeados com frequência. Mas rapidamente a vacina chegou e rapidamente estava no braço, "como assim"? Acho que as elites brasileiras ficaram surpresas com tamanha eficiência. Mas para isso acontecer, precisa ter a vacina.

Fátima: A eficiência poderia ter sido muito maior se a decisão fosse por comprar a vacina e por valorizar a vida.

Deisy: E mesmo assim demos um show, olha o que é distribuir uma vacina em quase todos os municípios brasileiros. Apesar de todas as falhas, que são do governo federal, e em alguns casos de governos estaduais ou municipais, pontualmente, como os problemas de distribuição, a gente já deu um show com o que tinha. 
Fátima: Aí é que entra a questão federativa, e a proatividade de alguns estados no enfrentamento à pandemia. Qual é a sua opinião, Deisy, sobre essas iniciativas de governos estaduais e, às vezes, até de alguns municípios, relativamente à busca de vacinas e de de insumos fora do país, à busca de cooperação internacional por parte de estados e municípios, tendo em vista exatamente essa omissão deliberada do governo em tomar essas providências. A gente gostaria de saber se vocês têm também uma documentação que trata desses assuntos.

Deisy: Não, não estudamos a atuação internacional dos estados e dos municípios, acompanhamos a legislação estadual. Nós obviamente acompanhamos o trabalho do Consórcio do Nordeste. Até hoje, 30 de junho de 2021, o Brasil não tem um comitê científico nacional para a Covid-19, é inimaginável isso. É certamente um dos poucos países, senão o único, que não possui um comitê científico nacional. Talvez um ou outro país não o tenha por que não tem condições, mas o Brasil deve ser um dos únicos que dispõe de todas as condições, mas não possui um comitê nacional. E considerando a qualidade dos cientistas e dos sanitaristas brasileiros, é uma afronta à população brasileira não termos um comitê científico nacional simplesmente porque o governo não quer seguir as orientações científicas para conter a pandemia. O governo não conseguiria convencer o comitê científico a espalhar a doença, o que já é um indício fundamental. Então o Nordeste fez o seu comitê científico e foi um excelente exemplo de, na falta de uma coordenação nacional, a constituição de um comitê científico que reúne e produz informações confiáveis, que orienta os governos. São decisões dificílimas de tomar, e tomadas na urgência, com consequências econômicas importantes. 0 fato de se defender a necessidade de adoção de medidas quarentenárias, em alguns casos, não significa que o pessoal da saúde pública ache que a melhor solução é a medida quarentenária. A solução é a medida quarentenária quando já se deixou a doença avançar, quando as estratégias de contenção tiveram obstáculos, pode acontecer, mas jamais vamos defender que a restrição de direitos seja generalizada. Essas medidas devem ser combinadas com uma série de outras medidas, inclusive a testagem massiva. Voltando ao Consórcio 
Nordeste, ter o apoio de um grupo de cientistas foi extremamente positivo, sob o prisma da comunicação com a opinião pública também, porque diante de uma pandemia, a questão não tem que ser o partido, a questão não tem que ser o governo, a questão não tem que ser eleitoral. Então quando há um comitê científico de pessoas que são independentes em relação ao governo, conversando com a população, a tendência é de que a mensagem passe mais, que as medidas não sejam apresentadas como apenas a ideia de um governante ou de um prefeito. Isso fortalece a todos, isso poderia ter acontecido em nível nacional, mas não aconteceu. Agora, quanto à busca de aquisição de insumos e de vacinas pelas unidades federativas, é uma prática muito ruim, é muito ruim para o país. É compreensível, mas é nefasto, porque podemos ter insumos em um determinado estado que é mais rico, e não em outros, e quando eu digo insumo aqui, estou falando de vacina, tratamento etc. Certamente isto aguçaria as desigualdades econômicas e sociais que já existem no país. Então não se pode comparar a capacidade de resposta que o estado de São Paulo, por exemplo, pode dar, com a de um estado com menos recursos ou com problemas específicos, como as dificuldades de acesso a determinadas localidades, caso da região Norte, ou de alguns lugares de qualquer região do Brasil que seja de difícil acesso. Existem fatores pontuais que determinam uma assimetria entre as capacidades de resposta, imagina um estado que está vacinando e um estado ao lado que não está vacinando, não só agrava as desigualdades, que do meu ponto de vista é o mais importante, mas também compromete a eficiência da estratégia de resposta, porque as pessoas circulam entre os estados, entre os municípios. Isso já aconteceu no ano passado, casos de uma cidade com suspensão de atividades não essenciais, porém as cidades contíguas sem restrições. Algumas vezes governos municipais tentaram restringir a circulação de pessoas mas o Judiciário manifestou-se desfavoravelmente. Mas a saúde pública nunca pode depender de um sistema repressivo, não há como reprimir mais de 200 milhões de pessoas, ao contrário, é a coordenação que deve acontecer. Eu entendo as motivações de quem foi comprar insumos, mas deve ser realmente o último recurso, porque a gente não pode ter 27 respostas a uma pandemia, se temos isso, já perdemos. E mais de 5.000 municípios, quando temos, já perdemos, e isso se explica pela ausência de coordenação nacional. 
Fátima: Isso é consequência da ausência de coordenação.

Deisy: Porque coordenar significa muito mais do que dar diretrizes, significa, do ponto de vista da estrutura do SUS, a realização de compras que são decisivas, ou seja, a manutenção de estoque de determinados produtos, é claro, as vacinas são hoje o exemplo mais evidente. Mas, realmente, esperar que os estados tenham que comprar é desastroso. A questão da produção das vacinas é muito interessante também, porque a Fiocruz e o Instituto Butantan são instituições que resistem, que conseguiram sobreviver aos respectivos governos. Porque também, a situação de São Paulo, antes da pandemia, a situação da educação superior e da pesquisa em São Paulo estava longe de ser um mar de rosas. Hoje parece que o governador de São Paulo é quem defende a ciência e o presidente da República é quem se opõe à ciência. Não é bem assim. Obviamente é positivo para a saúde pública que o governo estadual não tenha se alinhado ao governo federal na estratégia de disseminação do vírus. Entretanto, tanto o Butantan e como a Fiocruz resistem em conjunturas muito difíceis. Conseguiram construir alianças que possibilitaram a produção e a distribuição de vacinas. O Brasil é um país em via de desenvolvimento, não é um país desenvolvido, mas possui essas instituições que não surgem de uma hora para outra. Quero dizer que instituições como uma Fiocruz e um Butantan não podem ser criados de uma hora para a outra. Com a ideologização das políticas, a desvalorização dos profissionais e o corte de verbas, instituições como essas vão se encaminhando para uma paulatina destruição. Espero que as elites brasileiras se deem conta de que o apoio às instituições de pesquisa deve ser incondicional, porque a história deles nos colocou na posição de ser um dos poucos países em vias de desenvolvimento com capacidade de produção de vacinas. Já produzíamos outras vacinas, o Instituto Butantan é fornecedor do SUS há tanto tempo e de vacinas tão importantes. O que o governo Bolsonaro tentou fazer foi mudar o rumo da história pois o Instituto Butantan não produz vacina para São Paulo, ele produz vacina para o SUS. 
Fátima: Mas ele veio para destruir mesmo.

Deisy: O Butantan é provedor do SUS. Mas se o governo federal não quiser as vacinas... E aí depois quis, precisou das vacinas, e continua, infelizmente, atacando essas vacinas. Eu terminaria, Fátima, essa resposta, dizendo o seguinte: a extrema direita, historicamente, não teme as incoerências do seu discurso. A única preocupação da extrema direita atualmente no Brasil é a de se manter no poder a qualquer custo. E simplesmente como eles não estão preocupados com contradições, eles vão apresentar a vacinação como obra do governo federal e ao mesmo tempo ser contra a vacina. É isso que eles estão fazendo.

Deborah: Tem a vacina deles, a da China...

Deisy: É típico do negacionismo. Toda a questão é reabilitar no espaço público pessoas que cometeram atrocidades. Como é que os nazistas, como é que as pessoas que colaboraram com os nazistas, como é que os fascistas e os seus colaboradores voltariam a atuar no espaço público na Europa depois que a humanidade teve conhecimento da extensão das atrocidades que praticaram? Negando. Negando e, quando não é possível negar, banalizando, dizendo que não foi tão grave assim ou que as vítimas mereceram de alguma forma o destino que tiveram.

Fátima: Ou que cumpriram ordens.

Deisy: Também invertendo o ônus da prova, porque cada vez que alguém diz que o Holocausto não aconteceu ou que não teve tamanha extensão, porque são duas figuras retóricas diferentes, negar e banalizar, mas eles não hesitam em utilizar as duas. Primeiro negam, 
depois você prova que houve, e então banalizam: "não foi bem assim". Então, o objetivo é obrigar as vítimas a provar periodicamente que elas foram vítimas, é um inferno. E no caso da Covid-19 no Brasil nós vamos ter que seguir provando que essas mortes aconteceram, nós vamos ter que seguir provando o número de casos, eles estão sempre questionando. Um dos depoentes da CPI, Carlos Wizard, quando esteve por assumir um cargo no Ministério da Saúde, declarou que o número de óbitos por Covid-19 era "fantasioso" ou "manipulado", e anunciou uma recontagem ${ }^{10}$. $E$ isso é constante. $O$ episódio, que não entrou em nosso estudo porque ocorreu alguns dias depois da entrega, quando o presidente usa um relatório falso do TCU para questionar o número de mortes, estamos diante de negacionismo em estado bruto, fruto da aprendizagem com as extremas direitas, isso não é invenção deste governo.

Fátima: Você afirma que, contraditoriamente, ao mesmo tempo, eles negam a vacina e reivindicam a vacina. $E$, Deisy, vocês escreveram, e provaram que, na verdade, é uma política intencional, essa [...] da imunidade de rebanho, essa exposição deliberada de pessoas ao vírus, ao perigo e à morte. Sobre essa questão, eu queria te fazer uma pergunta, e você se sinta à vontade para me responder, se quiser. [...] Qual o nome que você daria para esse comportamento reiterado dos nossos governantes que expõem a população a essa situação toda que estamos vendo?

Deisy: Minha opinião técnica é que existem três dimensões criminais aqui. A mais evidente é o crime de responsabilidade, temos claramente um presidente da República que atenta contra os direitos fundamentais de sua população, inclusive o direito à vida; porque atenta contra o livre exercício dos demais Poderes da República e as unidades federativas; porque ameaça a segurança interna do país, e porque há incontáveis indícios de improbidade administrativa

\footnotetext{
${ }^{10}$ Secretário diz que Saúde recontará número 'fantasioso' de mortos da covid, Portal UOL, 05/06/2020, disponível em https://noticias.uol.com.br/saude/ultimas-noticias/redacao/2020/06/05/secretario-diz-quesaude-recontara-numero-fantasioso-de-mortos-da-covid.htm
} 
nesta gestão, e muito menos do que isso já foi considerado crime de responsabilidade no Brasil. Há, inclusive, uma série de pedidos de impeachment que citam o nosso estudo, inclusive o chamado "superpedido de impeachment"11.

Fátima: Eu estava vendo, estava muito interessante, porque tinha um amplo espectro da esquerda, passando pelo centro, até a direita, até a Joice Hasselmann estava lá. Fora Bolsonaro. Olha, parece que está se formando essa frente ampla necessária.

Deisy: Então existe essa primeira dimensão, de crime contra a responsabilidade, que é processada pelo Congresso Nacional, e que tem as travas que vocês conhecem. Há uma segunda dimensão, que é a do Código Penal brasileiro. No meu entendimento, é preciso investigar uma série de crimes, me parece que é clara a configuração de diversos deles. Falamos muito de prevaricação nesses últimos dias, mas existem os crimes relativos à saúde pública. O presidente coloca em risco a vida dos brasileiros por promover aglomerações em constante deslocamento pelo território nacional. Na estratégia federal há também a incitação para que não se adote medidas preventivas, e se desrespeite as autoridades locais e as autoridades sanitárias. Enfim, existe um conjunto de condutas que no meu entendimento configuram crimes comuns, e aí também o nosso estudo fundamentou diversas representações criminais que encontram obstáculo na Procuradoria Geral da República. Agora, não é por falta de queixa-crime, não é por falta de representação criminal, porque elas existem. E existe uma terceira esfera que é a do Direito Internacional, que é a minha formação original, que é a dimensão dos crimes contra a humanidade e do genocídio. Do ponto de vista técnico, não tenho dúvida de que estamos diante de crimes contra a humanidade em relação ao conjunto da população, segundo o Artigo 70 do Estatuto de Roma, e de genocídio em relação à população indígena, conforme o Artigo $6^{\circ}$. Mas dizer que deve ser investigado crime contra a humanidade e genocídio não significa necessariamente ir ao TPI [Tribunal Penal

${ }^{11}$ Disponível em https://www.superimpeachment.org/ 
Internacional] em Haia. O Estatuto de Roma é claríssimo: os Estados Partes têm o dever de cumprir as obrigações que assumiram. Um caso vai chegar ao TPI quando o Estado respectivo não puder ou não quiser realizar o julgamento. Então nós não precisamos ir até Haia, nós temos a obrigação de cumprir o Estatuto de Roma no âmbito da jurisdição brasileira. Porém, não sendo possível investigar aqui, evidentemente resta recorrer à Haia, e algumas entidades já apresentaram comunicações ao TPI neste sentido.

Fátima: Especialmente relativamente às populações indígenas.

Deisy: Tudo se agravou muito nas últimas semanas, então, quem antes reagia com espanto, inclusive jornalistas estrangeiros, afirmando "não é intencional, não pode ser tão diabólico assim", já não demonstra essa incredulidade. Tornou-se menos chocante falar em levar essa questão a Haia. Mas voltando ao meu ponto, o crime contra a humanidade ocorre em um contexto de ataque sistemático contra a população civil, que não precisa ser um conflito armado. Existe jurisprudência internacional no sentido de que o ataque pode ser inclusive o encorajamento de determinadas condutas de modo a causar danos à população. Para mim, claramente o ataque está acontecendo. Uma das hipóteses do art. $7^{\circ}$ do Estatuto de Roma refere atos desumanos que causem intencionalmente grande sofrimento, ou afetem gravemente a integridade física ou a saúde física ou mental das pessoas. Não tenho a menor dúvida da pertinência da investigação desse crime. E o genocídio, eu também não tenho dúvida em relação aos povos indígenas. Uma comunicação foi apresentada pela Comissão Arns e pelo Coletivo de Advogados pelos Direitos Humanos, o CADHU, em novembro de 2019, portanto anterior à pandemia. A pandemia agrava o contexto já existente de uma forma muito significativa. Mencionamos no estudo diversas ações do governo que podem ter resultado na propagação da doença em territórios indígenas. Mas me sinto cada vez mais propensa a discutir a possível prática de genocídio também em relação à população em geral. Eu acho que nós ainda precisamos avançar nessa discussão, mas a repercussão desproporcional da 
crise sanitária sobre a população preta e parda é evidente, ela está cabalmente comprovada. Haveria intenção de exterminar essa população? Porque a pergunta do genocídio é essa, a tipificação do genocídio é diferente da do crime contra a humanidade por isso, porque é preciso ter a intenção de eliminar um determinado grupo humano. Será que já não estaríamos em posição de constatar a intenção deliberada de eliminação dessa população? Creio que precisamos avançar nessa discussão. Ouvindo colegas que trabalham com a questão racial, eu já me pergunto se não é o caso de falar em genocídio da população negra. Em qualquer caso, o que importa é que haja investigação. O que não pode acontecer é que a luta pela responsabilização das autoridades federais se limite à apuração das denúncias de corrupção relacionadas à pandemia.

Fátima: É, isso é uma coisa que a gente tem que lamentar, 500.000 mortes não são suficientes para o impeachment, agora corrupção talvez seja.

Deisy: Há essa mudança de rumo na CPI, que eu espero que nos ajude a defender a necessidade de responsabilização, mas o fato é que as reações hoje são muito diferentes. Quando falávamos em crime contra a humanidade e genocídio éramos acusados inclusive de desconhecimento técnico, porque muitas pessoas pensavam que o TPI existia só para crimes de guerra, o que não é verdade, que ataque sistemático era só armado, não é verdade. Então, acho que está crescendo essa consciência, de que a tese dos crimes internacionais é pertinente do ponto de vista técnico há mais de um ano.

Fátima: É assustador. Eu fico muito impressionada, também, com a nossa incapacidade de imaginar que uma coisa assim viria. Não imaginávamos. Que estávamos vivendo uma crise de representação, sim, que estávamos vivendo uma crise democrática, sim, mas não que chegaríamos a isso tão rapidamente. Eu participo do INCT-PPED, coordenado pelo Renato Boschi e estamos discutindo a desconstrução das capacidades estatais por esses novos 
governos de extrema direita, e como é fácil desconstruir e difícil reconstruir. Quando estávamos preparando a sua entrevista, pensamos em discutir com você uma frase do Bolsonaro: "eu vim para destruir".

Deborah: A frase ipsis litteris é: “O Brasil não é um terreno aberto onde nós iremos construir coisas para o nosso povo, nós vamos desconstruir muita coisa". É quase o slogan do governo.

Fátima: E ele está fazendo isso: essa tentativa de acabar com o SUS, a escola, as universidades; as políticas públicas estão sendo absolutamente desconstruídas, coisas que demoraram décadas para se colocar de pé. Então, é nesse sentido que eu estou dizendo, não imaginávamos que chegaríamos a isso.

Deisy: Há muitos anos estudo crimes contra a humanidade, porque participei do movimento cívico pelo julgamento dos agentes públicos que cometeram crimes contra a humanidade durante o regime militar. Primeiro por minha formação em Direito Internacional, e depois por interesse nessa questão. E o que eu sempre achei assustador enquanto estudava casos como o genocídio em Ruanda ou os crimes praticados na ex-lugoslávia, tantas atrocidades, sempre me impressionou como as sociedades envolvidas toleravam esses crimes. Mas que eu pudesse ser agora testemunha de genocídio e crime contra a humanidade no meu próprio país, ver quantas pessoas foram coniventes e se calaram para que se pudesse chegar a esta situação é algo que não imaginei. Porque ninguém faz isso sozinho, a monstruosidade nunca é de uma pessoa só, essa monstruosidade é da sociedade. Eu não vou dizer no seu conjunto, porque é claro que houve resistência, muitos não silenciaram diante do que estava acontecendo, mas uma parcela importantíssima da sociedade silenciou, e uma outra colaborou diretamente. 
Fátima: E muita gente se indignou... Ficamos muito sem ferramentas, não é, Deisy? Com a pandemia, a questão de ocupar as ruas mesmo, só agora estamos conseguindo sair para protestar. Eu comentava, outro dia, com um colega meu, essa questão de ir para a rua pelo impeachment, contra o Bolsonaro, e ele falou: "ah, não vou, não vai ter impeachment, não tem força política no Congresso". Mas, gente, a política muda. Se não formos para rua, se não fizermos pressão, a política não muda. Sabemos que o centrão, essa frase não é minha, sabemos que o centrão não se compra, se aluga. Se o barco estiver afundando...

Deisy: E os ataques a quem resiste não param, não temos descanso. Não temos sequer um dia de paz. 